\title{
Zoledronic Acid and Its Calcium-contain Complexes in Treatment of Experimental Osteoporosis in Wistar Female Rats
}

\section{Povoroznyuk VV'1,Grygorieva VN ${ }^{1 *}$, Pekhnyo VI', Kozachkova OM² and Tsaryk NV ${ }^{2}$}

${ }^{1}$ D.F. Chebotarev Institute of Gerontology of the Ukrainian National Academy of Sciences, Kyiv Ukraine

${ }^{2}$ Institute of General and Inorganic Chemistry of the Ukrainian National Academy of Sciences, Kyiv, Ukraine

\begin{abstract}
The aim was to assess the composition, stability and biological activity of the complexes that are formed in the solution on the interaction of calcium ions with Zolendronic acid (Zol) and study their effects on bone mineral density (BMD) indexes in female rats with experimental osteoporosis. 40 reproductive Wistar rats with systemic osteoporosis which was modeled by oophorectomy were under the study. Animals were divided into 4 groups (I- did not receive any treatment with bisphosphonates, only sufficient consumption of calcium and vitamin $\mathrm{D}$ (Ca-D); II - receive single dose of Zol and Ca-D; III - soluble calcium complexes of Zol (Ca-Zol) without additional use of Ca-D; IV - soluble calcium complexes of Zol with Ca-D). BMD and bone mineral content (BMC) of total body and spine were measured before treatment, after 1 and 3 months of observation by X-ray densitometer "Prodigy". Our study showed the significant positive changes in total body BMD in 1 and 3 months and spine BMD in 3 months of observation $2^{\mathrm{d}}$ group. Analysis of BMD in rats of $3 \mathrm{~d}$ group has not shown any significant changes of spine and total body in 1 and 3 months after its injection. However, the administration of complexes calcium and Zol with Ca-D has positive effects on total body BMDs in 1 and 3 months' follow-up and spine BMD in 3 months of observation. Analysis of BMC indices in rats of $4^{\text {th }}$ group showed the positive changes in spine and total body indexes in 1 and 3 month of follow-up, however it was not found any significant differences with animal of $2^{\mathrm{d}}$ group. Conclusion investigated soluble complexes of calcium and Zol in combination with Ca-D supplementation showed positive effect on BMD and BMC indices, however, did not have any benefits in comparison standard administration of Zol with Ca-D supplementation.
\end{abstract}

Keywords: Zoledronic acid; Calcium-contain complex of zoledronic acid; Female rats; Bone mineral density; Osteoporosis

\section{Introduction}

Osteoporosis and its complications is an important medical and social problem that has a great impact on disability and mortality level in community [1-3]. The largest class for treatment of osteoporosis is bisphosphonates (BPs) that have the expressed antiresorbtive activity with effect on bone destruction (resorption) [1,4-6]. Different studies show that BPs inhibit bone resorption and they also slow down the process of bone loss, maintaining the bone mass, microstructure and strength in different site of skeleton in animals as well as in humans [13,7-12]. Nowadays, the various BPs have the different effectiveness that is from 1 to 2000 , that is connected with their anti-resorbtive properties due to their different chemical nature of substituent associated with bisphosphonic group $[1,6,13]$. The most active BPs include a nitrogencontaining heterocycle, particularly Zoledronic acid (Zol, $\left.\mathrm{H}_{4} \mathrm{~L}\right)$, that showed its clinical efficacy in numerous experimental and randomized, placebo-controlled studies [2-5]. However, at this time in order to improve biological activity and efficiency of BPs in clinical practice, the investigators are conducting the modification of BPs by different substituent and studying their impact on the change in the biological activity [2-5]. Thus, there is a great need to develop new compounds of BPs, including Zol. Usually in treatment of postmenopausal and senile osteoporosis all BPs are administered with sufficient consumption of calcium and vitamin D (respectively $1000 \mathrm{mg} / \mathrm{d}$ and 400-800 IU/d) [1-3]. This becomes the grounds to investigate the therapeutic efficacy of soluble complexes of bisphosphonic acid with calcium. The combination BPs with calcium in one complex compound gives the prerequisites to predict except anti-resorbtive action (due to the presence of bisphosphonic acid) additional positive effect of calcium and vitamin $\mathrm{D}$ (which affects the bone remodeling process, including its mineralization). The aim of this study was to investigate the composition, stability and biological activity of the complexes that are formed in the solution on the interaction of calcium ions with $\mathrm{Zol}$ and compare their effects on bone mineral density indexes in female rats with experimental osteoporosis.

\section{Materials and Methods}

The study was conducted on 40 reproductive [14] female Wistar rats (4 groups, 10 animals in each group. The age of the rats at the time of study enrollment -4 months, body weight is $200 \pm 10 \mathrm{~g}$ ). The rats existed under natural light and a standard diet with free access to food (standard granulated feed-concentrate) and water. This experimental study was performed at "Institute of gerontology named after D. F. Chebotarev NAMS Ukraine" and was conducted according to the rules of the European Convention for the humane treatment of animals [15]. Systemic postmenopausal osteoporosis was modeled by bilateral oophorectomy with fitting ether anesthesia. Osteoporosis therapy was started 4 months after the surgery. Animals were divided into 4 groups depending on the type of treatment: the first group did not receive any treatment with BPs, only sufficient consumption of calcium and vitamin $\mathrm{D}$ from diet $(\mathrm{Ca} / \mathrm{D})$. The second group received a single dose of $\mathrm{Zol}$ (in parenteral (intra-abdominal) solution) and calcium and vitamin D supplementation with diet $(\mathrm{Zol}+\mathrm{Ca} / \mathrm{D})$. The third group has got calcium complexes of $\mathrm{Zol}(\mathrm{Ca}-\mathrm{Zol})$ in solution parenterally once without

*Corresponding author: Grygorieva VN, Institute of Gerontology, Kyiv, Ukraine, Tel: 0442541550; E-mail: crystal_ng@ukr.net

Received: September 28, 2017; Accepted: October 16, 2017; Published October 25, 2017

Citation: Povoroznyuk VV,Grygorieva VN, Pekhnyo VI, Kozachkova OM, Tsaryk NV (2017) Zoledronic Acid and Its Calcium-contain Complexes in Treatment of Experimental Osteoporosis in Wistar Female Rats. Biochem Anal Biochem 6: 340. doi: 10.4172/2161-1009.1000340

Copyright: @ 2017 Povoroznyuk VV, et al. This is an open-access article distributed under the terms of the Creative Commons Attribution License, which permits unrestricted use, distribution, and reproduction in any medium, provided the original author and source are credited. 
additional use of calcium and vitamin $\mathrm{D}$ from diet. The fours group received calcium complexes of Zol in solution once intra-abdominally with calcium and vitamin D supplementation with $\operatorname{diet}(\mathrm{Ca}-\mathrm{Zol}+\mathrm{Ca} / \mathrm{D})$. Zoledronic acid monohydrate, a commercial drug (Sigma Aldrich), and $\mathrm{Ca}\left(\mathrm{NO}_{3}\right)_{2} \cdot 4 \mathrm{H}_{2} \mathrm{O}$ (Sigma Aldrich) were used in the work.

The $\mathrm{pH}$ potentiometric titration of a solution of the system $\mathrm{Ca}\left(\mathrm{NO}_{3}\right)_{2}: \mathrm{Zol}=1: 1$ was performed with a carbonate-free $0.02 \mathrm{~mol} / \mathrm{L}$ $\mathrm{KOH}$ solution at $20 \pm 0.1^{\circ} \mathrm{C}$. The concentration of $\mathrm{Ca}\left(\mathrm{NO}_{3}\right)_{2}$ and $\mathrm{Zol}$ in initial solution was $1 \cdot 10^{-3} \mathrm{~mol} / \mathrm{L}$, the initial volume of the solution was $20 \mathrm{~mL}$. The ionic strength was $0.15 \mathrm{~mol} / \mathrm{L} \mathrm{KCl}$. The $\mathrm{pH}$ of the solutions was measured with a Metrohm $827 \mathrm{lab} \mathrm{pH}$ meter at $20 \pm 0.1^{\circ} \mathrm{C}$. The $\mathrm{pH}$ meter was calibrated using standard buffer solutions with $\mathrm{pH} 1.68$, 4.01, 6.86 and 9.18, taking into account the dependence of their $\mathrm{pH}$ on temperature. The formation constants of calcium complexes with $\mathrm{Zol}$ and their equilibrium concentrations were calculated using the PSEQUAD program [16] and $\mathrm{pH}$ potentiometric data from the formula: $\AA=\left[M_{x} L_{y} H_{z}\right] /[M]^{x}[L]^{y}[H]^{z}$.

To study the therapeutic action of $\mathrm{Zol}$ and its complexes with calcium, solutions containing $\mathrm{Zol}$ and $\mathrm{Ca}\left(\mathrm{NO}_{3}\right)_{2}$ in equimolar ratio (1:1) were prepared. The $\mathrm{LD}_{50}$ of the Mebiphon (methylene bisphosphonic acid disodium salt), which was $\sim 160 \mathrm{mg} / \mathrm{kg}$ for rats in the case of intraperitoneal injection, was taken as a rough value of $\mathrm{LD}_{50}$ [17]. Based on the average weight of rats of $200 \mathrm{~g}$ at the beginning of therapy, the dose of the bisphosphonic acid under investigation for one rat was $0.75 \mathrm{mg}$. The test solutions had a Zol concentration of $0.75 \mathrm{mg} /$ $\mathrm{mL}\left(3.35 \times 10^{-3} \mathrm{~mol} / \mathrm{L}\right)$ and an equimolar concentration of $\mathrm{Ca}\left(\mathrm{NO}_{3}\right)_{2}$ $\left(3.35 \times 10^{-3} \mathrm{~mol} / \mathrm{L}\right)$. All tested solution containing $\mathrm{Zol}$ and its complexes with calcium were injected by intraperitoneal administration in sterile conditions. Calcium and vitamin D was added to the diet along 3 months of observation period starting from the date of the start of treatment in all groups. In vivo assessment of bone parameters was performed using dual-photon X-ray densitometry "Prodigy" (GE Medical systems, Model 8743. 2005; USA; program "Experimental animals"), which allows to measure the bone mineral density (BMD) and bone mineral content (BMC) of different parts of skeleton in small animals. We have measure these parameters in spine and total body. The measuring was performed three times (before treatment, after 1 and 3 months of observation) with fixation of the animal using a special device and ether anesthesia. BMD and BMC indexes in studied regions of the rats' skeleton of all groups before treatment were not significantly different. BMD measurement error using the DXA was $\pm 0.01 \mathrm{~g} /$ $\mathrm{cm}^{2}$. Statistical analysis was performed using the software package "Statistisa 6.0" Copyright ${ }^{\odot}$ StatSoft. Inc. 1984-2001, Serial number 31415926535897. We used the following methods of statistical analysis: comparing the means - by Student's t-test for independent groups, evaluation of parameters' dynamics in group - by Student's t-test for dependent samples. Data are presented as $\mathrm{M} \pm \mathrm{SD}$. The critical level of significance for statistical hypotheses testing considered $\mathrm{p}<0.05$.

\section{Results}

Zol is a complexone containing two phosphonic groups, a hydroxyl group and an imidazole residue. Zol exists in the zwitterionic form with localization of negative charge on the phosphonate group and with positive charge delocalized on the imidazole ring atoms. According to the data of $\mathrm{pH}$ potentiometric titration, $\mathrm{Zol}$ is a tetrabasic acid $\left(\mathrm{H}_{4} \mathrm{~L}\right)$, for which the formation constants of protonated forms and dissociation constants have been calculated (Table 1) [18]. The formation constants of calcium complexes with $\mathrm{Zol}$ of the equimolar compositions [CaHL] $(\lg \beta=16.11(0.06))$ and $[\mathrm{CaL}]^{2-}(\lg \beta=9.60(0.06))$ have been calculated from the data of two parallel $\mathrm{pH}$ titrations of the system $\mathrm{Ca}\left(\mathrm{NO}_{3}\right)_{2}$ :
Zol=1:1 (each curve contained over 50 points). In these complexes, Zol is coordinated to calcium by two oxygen atoms of phosphonic groups (Figure 1).

This assumption is supported by the fact that in calcium complexes with Zol and in complexes of alkali and 3d-metals with Zol in the crystalline state, the nitrogen atom of the imidazole ring of the ligand are not involved in coordination to the metal ion [19-21]. Using the calculated formation constants of calcium complexes with Zol, a diagram of the equilibrium distribution of complexes of different composition as a function of $\mathrm{pH}$ in the system $\mathrm{Ca}\left(\mathrm{NO}_{3}\right)_{2}: \mathrm{Zol}=1: 1$ has been constructed (Figure 2).

It is seen from the diagram that the complex formation of calcium with $\mathrm{Zol}$ in $0.15 \mathrm{~mol} / \mathrm{L} \mathrm{KCl}$ begins at $\mathrm{pH}$ over 5 , and that at the physiological $\mathrm{pH}$ value, the complex $[\mathrm{CaHL}]^{-}$and $[\mathrm{CaL}]^{2-}$ anions are in equilibrium in the solution. This allows us to investigate the biological activity of the calcium complexes with Zol, which are formed in the solutions containing $\mathrm{Ca}\left(\mathrm{NO}_{3}\right)_{2}: \mathrm{Zol}=1: 1$ system.

Analysis of BMD indices in female rats after bilateral oophorectomy which received only calcium and vitamin $\mathrm{D}$ supplementation with diet did not reveal their positive dynamics at the spine and total body in 1 and 3 months of observation (Table 2). The combined therapy with Zol and additional supplementation of calcium and vitamin D also did not show any significant differences in BMD indexes of the spine in 1 months of follow-up, however it was observed after 3 months after

\begin{tabular}{|c|c|c|c|c|}
\hline \multicolumn{4}{|c|}{$\lg \beta \mathrm{HzL}$} & \multirow{2}{*}{$\begin{array}{l}\text { Determination } \\
\text { conditions }\end{array}$} \\
\hline [HL]3- & [H2L]2- & [H3L]- & [H4L] & \\
\hline 11.07 & $19.25(0,03)$ & $25.24(0,04)$ & 27.78 & \multirow{3}{*}{$\begin{array}{c}0,15 \mathrm{~mol} / \mathrm{L} \mathrm{KCl}, \\
20^{\circ} \mathrm{C}\end{array}$} \\
\hline pK4 & pK3 & pK2 & pK1 & \\
\hline 11.07 & 8.18 & 5.99 & 2.54 & \\
\hline
\end{tabular}

Table 1: Formation constants of protonated Zol forms and dissociation constants.
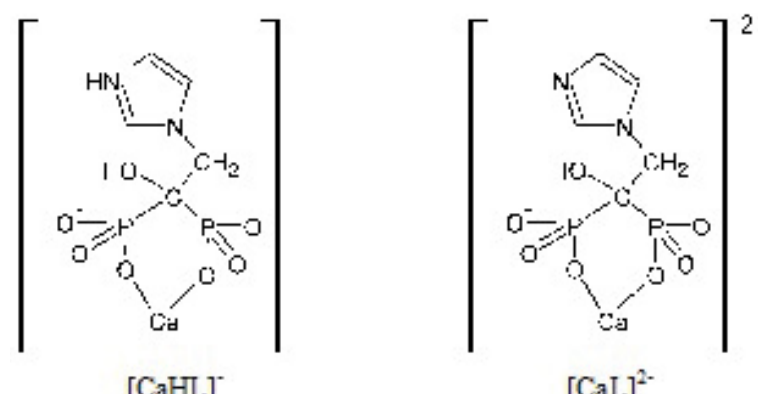

$[\mathrm{CaL}]^{2-}$

Figure 1: Complexes of zoledronic acid and calcium.

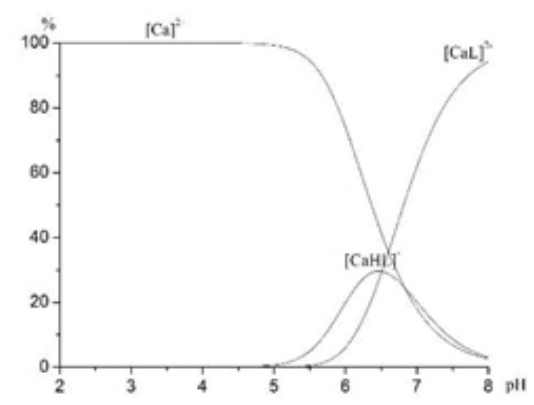

Figure 2: Diagram of the equilibrium distribution of complexes of different composition as a function of $\mathrm{pH}$ in the system $\mathrm{Ca}\left(\mathrm{NO}_{3}\right)_{2}: \mathrm{Zol}=1: 1(\mathrm{CCa}(\mathrm{II})=\mathrm{CZ}$ ol $=1.10^{-3} \mathrm{~mol} / \mathrm{L}$ ) in $0.15 \mathrm{~mol} / \mathrm{L} \mathrm{KCl}$. 
Citation: Povoroznyuk VV,Grygorieva VN, Pekhnyo VI, Kozachkova OM, Tsaryk NV (2017) Zoledronic Acid and Its Calcium-contain Complexes in Treatment of Experimental Osteoporosis in Wistar Female Rats. Biochem Anal Biochem 6: 340. doi: 10.4172/2161-1009.1000340

Page 3 of 5

\begin{tabular}{|c|c|c|c|c|c|c|c|c|c|c|}
\hline \multirow[b]{2}{*}{ Groups/Indices } & \multicolumn{5}{|c|}{ Spine BMD } & \multicolumn{5}{|c|}{ Total body BMD } \\
\hline & Before treatment & After treatment & Dynamics & $\mathbf{t}$ & $\mathbf{P}$ & Before treatment & After treatment & Dynamics & $\mathbf{t}$ & p \\
\hline & \multicolumn{10}{|c|}{ In one month } \\
\hline I (Ca/D) & $0.133 \pm 0.009$ & $0.132 \pm 0.012$ & $-0.001 \pm 0.014$ & 0.15 & 0.89 & $0.098 \pm 0.006$ & $0.102 \pm 0.006$ & $0.003 \pm 0.008$ & 1.16 & 0.28 \\
\hline II (Zol+ Ca/D) & $0.132 \pm 0.010$ & $0.137 \pm 0.007$ & $0.004 \pm 0.013$ & 1.08 & 0.31 & $0.098 \pm 0.005$ & $0.104 \pm 0.003$ & $0.006 \pm 0.005$ & 3.58 & 0.006 \\
\hline III (Ca-Zol) & $0.121 \pm 0.040$ & $0.136 \pm 0.012$ & $0.015 \pm 0.046$ & 1.05 & 0.32 & $0.102 \pm 0.011$ & $0.104 \pm 0.007$ & $0.001 \pm 0.008$ & 0.52 & 0.61 \\
\hline \multirow[t]{2}{*}{ IV (Ca-Zol + Ca/D) } & $0.127 \pm 0.010$ & $0.135 \pm 0.010$ & $0.008 \pm 0.013$ & 1.74 & 0.13 & $0.095 \pm 0.008$ & $0.100 \pm 0.005$ & $0.006 \pm 0.005$ & 3.06 & 0.02 \\
\hline & \multicolumn{10}{|c|}{ In three months } \\
\hline I (Ca/D) & $0.135 \pm 0.007$ & $0.115 \pm 0.046$ & $-0.019 \pm 0.044$ & 1.17 & 0.29 & $0.099 \pm 0.006$ & $0.102 \pm 0.006$ & $0.003 \pm 0.008$ & 1.03 & 0.34 \\
\hline II (Zol+ Ca/D) & $0.132 \pm 0.010$ & $0.142 \pm 0.013$ & $0.009 \pm 0.013$ & 2.33 & 0.045 & $0.098 \pm 0.005$ & $0.108 \pm 0.007$ & $0.010 \pm 0.007$ & 4.53 & 0.001 \\
\hline III (Ca-Zol) & $0.121 \pm 0.040$ & $0.134 \pm 0.012$ & $0.013 \pm 0.045$ & 0.94 & 0.37 & $0.102 \pm 0.011$ & $0.108 \pm 0.008$ & $0.006 \pm 0.011$ & 1.63 & 0.14 \\
\hline IV (Ca-Zol + Ca/D) & $0.127 \pm 0.010$ & $0.140 \pm 0.010$ & $0.013 \pm 0.016$ & 2.31 & 0.049 & $0.095 \pm 0.008$ & $0.112 \pm 0.006$ & $0.018 \pm 0.008$ & 6.29 & 0.0004 \\
\hline
\end{tabular}

Note: I $(\mathrm{Ca} / \mathrm{D})$ - the group of female rats that received only calcium and vitamin $\mathrm{D}$ in supplement; II (Zol+Ca/D) - the group of rats that have got Zoledronic acid in combination with calcium and vitamin D supplementation; III (Ca-Zol) - the group that received complexes of Zoledronic acid with calcium and without additional calcium and vitamin D supplementation; IV $(\mathrm{Ca}-\mathrm{Zol}+\mathrm{Ca} / \mathrm{D})$ - the group that have got complexes of Zoledronic acid with calcium and additional calcium and vitamin D supplementation.

Table 2: Bone mineral density of spine and total body in female rats with experimental osteoporosis after treatment by different complex of zolendronic acid, g/cm².

\begin{tabular}{|c|c|c|c|c|c|c|c|c|c|c|}
\hline \multirow{3}{*}{ Groups/Indices } & \multicolumn{5}{|c|}{ Spine BMC } & \multicolumn{5}{|c|}{ Total body BMC } \\
\hline & $\begin{array}{c}\text { Before } \\
\text { treatment }\end{array}$ & After treatment & Dynamics & $\mathbf{t}$ & $\mathbf{P}$ & $\begin{array}{l}\text { Before } \\
\text { treatment }\end{array}$ & After treatment & Dynamics & $\mathbf{t}$ & $\mathbf{p}$ \\
\hline & \multicolumn{10}{|c|}{ In one month } \\
\hline $\mathrm{I}(\mathrm{Ca} / \mathrm{D})$ & $2.18 \pm 0.31$ & $2.46 \pm 0.37$ & $0.29 \pm 0.54$ & 1.5 & 0.18 & $11.08 \pm 0.71$ & $11.80 \pm 0.83$ & $0.72 \pm 0.88$ & 2.32 & 0.053 \\
\hline II (Zol+ Ca/D) & $2.18 \pm 0.45$ & $2.46 \pm 0.31$ & $0.28 \pm 0.58$ & 1.53 & 0.16 & $11.55 \pm 0.87$ & $12.39 \pm 0.71$ & $0.84 \pm 0.68$ & 3.91 & 0.004 \\
\hline III (Ca-Zol) & $2.44 \pm 0.48$ & $2.55 \pm 0.54$ & $0.11 \pm 0.27$ & 1.3 & 0.23 & $11.73 \pm 1.38$ & $12.17 \pm 1.12$ & $0.44 \pm 0.83$ & 1.67 & 0.13 \\
\hline \multirow[t]{2}{*}{$\begin{array}{c}\text { IV (Ca-Zol + } \\
\text { Ca/D) }\end{array}$} & $2.23 \pm 0.21$ & $2.60 \pm 0.26$ & $0.38 \pm 0.24$ & 4.47 & 0.003 & $11.56 \pm 0.74$ & $12.26 \pm 0.76$ & $0.70 \pm 0.69$ & 2.87 & 0.02 \\
\hline & \multicolumn{10}{|c|}{ In three months } \\
\hline $\mathrm{I}(\mathrm{Ca} / \mathrm{D})$ & $2.20 \pm 0.32$ & $2.36 \pm 0.24$ & $0.16 \pm 0.43$ & 0.97 & 0.37 & $11.11 \pm 0.76$ & $12.13 \pm 0.79$ & $1.02 \pm 1.10$ & 2.45 & 0.049 \\
\hline II (Zol+ Ca/D) & $2.18 \pm 0.45$ & $2.5 \pm 0.35$ & $0.32 \pm 0.48$ & 2.1 & 0.06 & $11.55 \pm 0.87$ & $12.68 \pm 0.79$ & $1.13 \pm 0.88$ & 4.04 & 0.003 \\
\hline III (Ca-Zol) & $2.44 \pm 0.48$ & $2.63 \pm 0.31$ & $0.19 \pm 0.55$ & 1.1 & 0.3 & $11.73 \pm 1.38$ & $12.61 \pm 1.15$ & $0.88 \pm 1.16$ & 2.4 & 0.04 \\
\hline $\begin{array}{c}\text { IV (Ca-Zol + } \\
\text { Ca/D) }\end{array}$ & $2.23 \pm 0.21$ & $2.81 \pm 0.35$ & $0.59 \pm 0.40$ & 4.18 & 0.004 & $11.56 \pm 0.74$ & $12.89 \pm 0.38$ & $1.33 \pm 0.92$ & 4.08 & 0.005 \\
\hline
\end{tabular}

Note: I (Ca/D) - the group of female rats that received only calcium and vitamin $D$ in supplement; II (Zol+Ca/D) - the group of rats that have got Zoledronic acid in combination with calcium and vitamin D supplementation; III (Ca-Zol) - the group that received complexes of Zoledronic acid with calcium and without additional calcium and vitamin D supplementation; IV $(\mathrm{Ca}-\mathrm{Zol}+\mathrm{Ca} / \mathrm{D})$ - the group that have got complexes of Zoledronic acid with calcium and additional calcium and vitamin D supplementation.

Table 3: Bone mineral content of spine and total body in female rats with experimental osteoporosis after treatment by different complex of zolendronic acid.

Zol administration (BMD dynamic amounted $0.009 \pm 0.013 \mathrm{~g} / \mathrm{cm}^{2}$ $(\mathrm{p}=0.045))$ (Table 2). Furthermore, we have found the reliable changes in total body BMD in 1 and 3 months of observation (BMD dynamic amounted $0.006 \pm 0.005 \mathrm{~g} / \mathrm{cm}^{2}(\mathrm{p}=0.006)$ in 1 month and $0.010 \pm 0.007$ $\mathrm{g} / \mathrm{cm}^{2}$ ( $\left.\mathrm{p}=0.001\right)$ in 3 months accordingly). Analysis of DXA indices in female rats received the soluble complexes calcium and Zol without additional of calcium and vitamin $\mathrm{D}$ administration has not shown any significant changes of spine and total body BMD in 1 and 3 months after its injection (Table 2). However, the administration the complexes calcium and Zol with calcium and vitamin D supplementation has positive effects on total body BMDs in 1 or 3 months' follow-up (BMD dynamics composed $0.006 \pm 0.005 \mathrm{~g} / \mathrm{cm}^{2}(\mathrm{p}=0.02)$ and $0.018 \pm 0.008 \mathrm{~g} /$ $\mathrm{cm}^{2}(\mathrm{p}=0.0004)$ accordingly).

We have also found the significant positive changes of BMD index of spine in 3 months of observation in female rats that received complex calcium and Zol with calcium and vitamin D supplementation. Furthermore, we did not establish any significant changes between BMD parameters after 1 and 3 months of observation in dependence on additional calcium and vitamin $\mathrm{D}$ supplementation in female rats which received complex of calcium and Zol (III and IV group). Analysis of spine BMC indexes of female rats after bilateral oophorectomy did not show any dynamics in 1 and 3 months' follow-up depend on types of therapy that deny the negative effects these treatment regimens on bone mineralization in spine in these periods of time. We did not find any significant differences in spine BMC indexes after 1 or 3 months' followup in female rats with experimental osteoporosis that receive calcium and vitamin D supplementation alone (I group). Furthermore, it was shown the positive tendency in total bode BMC dynamics in 1 month of observation and significant different after 3 month of observation (BMC dynamics composed $1.02 \pm 1.10 \mathrm{~g}, \mathrm{p}=0.0049$ ). Also we did not establish any negative effects in spine BMC indexes after 1 or 3 months' follow-up (Table 3 ) in rats that receive Zol with calcium and vitamin D supplementation (II group). Moreover, we have found the reliable changes in BMC indexes of total body in female rats with experimental osteoporosis after 1 or 3 months' follow-up, which have got Zol in combination with calcium and vitamin D supplementation (Table 3). Administration of soluble complex calcium and Zol and without additional use of calcium and vitamin D did not lead any significant changes in spine BMC indexes after 1 and 3 months of treatment and total body BMC index in female rats after bilateral oophorectomy after 1 month of observation. However, we have found significant increase of total body BMC index after 3 months of follow-up in female rats with experimental osteoporosis that received this complex without additional administration of calcium and vitamin D (BMC dynamics composed $0.88 \pm 1.16 \mathrm{~g}, \mathrm{p}=0.04$ ) (Table 3). Analysis of BMD indices in female rats after bilateral oophorectomy which received soluble 
Citation: Povoroznyuk VV,Grygorieva VN, Pekhnyo VI, Kozachkova OM, Tsaryk NV (2017) Zoledronic Acid and Its Calcium-contain Complexes in Treatment of Experimental Osteoporosis in Wistar Female Rats. Biochem Anal Biochem 6: 340. doi: 10.4172/2161-1009.1000340

Page 4 of 5

complex calcium and Zol in combination with calcium and vitamin D supplementation (IV group) showed the significant positive changes in spine and total body BMC indexes in 1 and 3 month of follow-up.

\section{Discussion}

Osteoporosis is an important skeletal disease characterized by low bone mass and microarchitectural deterioration of bone tissue with a resulting increase in bone fragility and risk of fractures [1,2]. It is a considerable public health issue. Low-trauma fractures are the clinical consequence of osteoporosis and are major cause of morbidity and mortality and health expenditure worldwide. Bisphosphonates are the largest class of anti-resorbtive agents with are widely used in clinical practice. Nowadays, there are different generations of bisphosphonates with various types of prescription. For treatment of osteoporosis all of them usually are administered with sufficient consumption of calcium and vitamin D (respectively $1000 \mathrm{mg} / \mathrm{d}$ and 400-800 IU/d) [1-3]. This becomes the grounds to investigate the therapeutic efficacy of soluble complexes of bisphosphonic acid with calcium. New bisphosphonic acids were found during previous years [22-27], nevertheless, there is a great need to develop new compounds of BPs, including ones from different generation. The aim of this study was to investigate the composition, stability and biological activity of the complexes that are formed in the solution on the interaction of calcium ions with Zol and compare their effects on bone mineral density indices in female rats with experimental osteoporosis. Our analysis showed that BMD indices in female rats after bilateral oophorectomy which received only calcium and vitamin $\mathrm{D}$ supplementation with diet were not changed at the spine and total body in 1 and 3 months of observation confirming the literature data [1-3] about the small and insufficient efficacy of calcium and vitamin D use only in treatment of postmenopausal osteoporosis. The combined therapy with Zol and additional supplementation of calcium and vitamin $\mathrm{D}$ also did not show any significant differences in BMD indexes of the spine in 1 months of follow-up, however it was observed in 3 months after Zol administration. Furthermore, we have found the significant changes in total body BMD in 1 and 3 months of observation that confirms the literature data $[3,10]$ about expressed effect of Zol in combination with sufficient calcium and vitamin D supplementation in the treatment of osteoporosis. Analysis of DXA indices in female rats received the soluble complexes calcium and Zol without additional of calcium and vitamin D administration has not shown any significant changes of spine and total body BMD in 1 and 3 months after its injection that confirmed the necessity of combined therapy. However, the administration of complexes calcium and Zol with calcium and vitamin D supplementation has positive effects on total body BMDs in 1 or 3 months' follow-up. Furthermore, we have found the significant positive changes of BMD index of spine in 3 months of observation in female rats that received complexes calcium and Zol with calcium and vitamin D supplementation, Some studies showed that bisphosphonates have shown the influence on mineralization of bone tissue due to decreased bone turnover rates and the prolongation of secondary mineralization $[3,10]$. We did not find any reliable differences in spine BMC indexes after 1 or 3 months' follow-up in female rats with experimental osteoporosis that receive calcium and vitamin $\mathrm{D}$ supplementation alone. Analysis of spine BMC indexes of female rats after bilateral oophorectomy did not show any dynamics in 1 and 3 months' follow-up depend on types of therapy that deny the negative effects these treatment regimens on bone mineralization in spine in these periods of time. Furthermore, it was shown the positive tendency in total body BMC dynamics in 1 month of observation and significant different after 3 month of observation. Also we did not establish any negative effects in spine BMC indexes after 1 or 3 months' follow-up in rats that receive Zol with calcium and vitamin $\mathrm{D}$ supplementation.
Moreover, we have found the reliable differences in BMC indexes of total body in female rats with experimental osteoporosis after 1 or 3 months' follow-up, which have got Zol in combination with calcium and vitamin D supplementation. Administration of soluble complexes calcium and Zol and without additional use of calcium and vitamin $\mathrm{D}$ did not lead any significant changes in spine BMC indexes after 1 and 3 months of treatment and total body BMC index in female rats after bilateral oophorectomy after 1 month of observation. However, we have found significant increase of total body BMC index after 3 months of follow-up in female rats with experimental osteoporosis that received this complexes without additional administration of calcium and vitamin D. Analysis of BMC indices in female rats after bilateral oophorectomy which received soluble complexes of calcium and Zol in combination with calcium and vitamin D supplementation showed the positive changes in spine and total body BMC indexes in 1 and 3 month of follow-up. In conclusion, our study has shown that investigated soluble complexes of calcium and $\mathrm{Zol}$ in combination with Ca-D supplementation showed positive effect on BMD and BMC indices however did not have any benefits in comparison standard administration of Zol with Ca-D supplementation.

\section{Acknowledgements}

We are grateful for the collaboration of the group of scientists of "Institute of Gerontology named after D. F. Chebotarev of NAMS Ukraine" (Kyiv, Ukraine) who performed bilateral oophorectomy and DXA measurement.

\section{References}

1. Povoroznyuk VV, Grygorieva NV, Orlyk TV (2014) Osteoporosis in the practice of internist doctor. Express, Kyiv Russian.

2. Kanis JA, McCloskey EV, Johansson H, Cooper C, Rizzoli R, et al. (2013) European guidance for the diagnosis and management of osteoporosis in postmenopausal women. Osteoporosis International 24: 23-57.

3. Camacho PM, Petak SM, Binkley N, Clarke BL, Harris ST, et al. (2016) American Association of Clinical Endocrinologists and American College of Endocrinology Clinical practice guidelines for the diagnosis and treatment of postmenopausal osteoporosis. Endocr Pract 22: 1-42.

4. Zhou J, Ma X, Wang T, Zhai S (2016) Comparative efficacy of bisphosphonates in short-term fracture prevention for primary osteoporosis: a systematic review with network meta-analyses. Osteoporos Int 27: 3289-3300.

5. Sanderson J, Martyn-St JM, Stevens J, Goka E, Wong R, et al. (2016) Clinica effectiveness of bisphosphonates for the prevention of fragility fractures: A systematic review and network meta-analysis. Bone 89: 52-58.

6. Peng J, Liu Y, Chen L, Peng K, Xu Z, et al. (2016) Bisphosphonates can prevent recurrent hip fracture and reduce the mortality in osteoporotic patient with hip fracture: A meta-analysis. Pak J Med Sci 32: 499-504.

7. Dhillon S (2016) Zoledronic Acid A Review in Osteoporosis. Drugs 76: 16831697.

8. Vermeer J, Renders G, van Duin MA, Jansen I, Bakker LF, et al. (2016) Bonesite-specific responses to zoledronic acid. Oral Dis Oct 5 .

9. Günes N, Dundar S, Saybak A, Artas G, Acikan I, et al. (2016) Systemic and local zoledronic acid treatment with hydroxyapatite bone graft: A histological and histomorphometric experimental study. Exp Ther Med. 12: 2417-2422.

10. Cui M, Yu LZ, Zhang N, Wanq LJ, Sun J, et al. (2016) Zoledronic Acid Improves Bone Quality in the Streptozotocin-Induced Diabetes Rat through Affecting the Expression of the Osteoblast-Regulating Transcription Factors. Exp Clin Endocrinol Diabetes.

11. Curtis RC, Custis JT, Ehrhart NP, Ehrhart EJ, Condon KW, et al. (2016) Combination Therapy with Zoledronic Acid and Parathyroid Hormone Improves Bone Architecture and Strength following a Clinically-Relevant Dose of Stereotactic Radiation Therapy for the Local Treatment of Canine Osteosarcoma in Athymic Rats. PLoS One 11: e0158005.

12. Zhou J, Wang T, Zhao X, Donald RM, Zhai S (2016) Comparative Efficacy of Bisphosphonates to Prevent Fracture in Men with Osteoporosis: A Systematic Review with Network Meta-Analyses. Rheumatol Ther 3: 117-128. 
Citation: Povoroznyuk VV,Grygorieva VN, Pekhnyo VI, Kozachkova OM, Tsaryk NV (2017) Zoledronic Acid and Its Calcium-contain Complexes in Treatment of Experimental Osteoporosis in Wistar Female Rats. Biochem Anal Biochem 6: 340. doi: 10.4172/2161-1009.1000340

Page 5 of 5

13. Serrano AJ, Begoña L, Anitua E, Cobos R, Orive G (2013) Systematic review and meta-analysis of the efficacy and safety of alendronate and zoledronate for the treatment of postmenopausal osteoporosis. Gynecol Endocrinology 29 : $1005-1014$.

14. Povoroznyuk VV, Deduh NV, Grygorieva NV, Gopkalova IV (2012) Experimental osteoporosis. Express (Kyiv). Russian.

15. Council of Europe (1986) European convention for the protection of vertebrate animals used for experimental and other scientific purpose. Strasbourg 52.

16. Zekany L, Nagypal I (1985) Computational methods for the determination of formation constants. Plenum Press: New York 291-353.

17. Komisarenko SV, Sharykina NI, Lozynskyi MO (2001) Patent number UA 40714. Antitumor agent (mebiphon) Russian.

18. Kozachkova AN, Tsarik NV, Kutsenko IP, Trachevsky VV, Rozhenko AB (2013) Interaction between palladium(II) and [1-hydroxy-2-(1H-imidazol1 -yl)ethylidene] bisphosphonic (zoledronic) acid in aqueous solutions at physiological chloride ion concentration. Ukr Chim J 79: 27-32.

19. Freire E, Vega D, Baggio R (2010) Zoledronate complexes. II. catenaPoly[[tetraaquabis[hemihydrogen $\mu 3$-1-hydroxy-2-(imidazol-3-ium-1-yl) ethylidene-1,1-diphosphonatok-3O:O':O"]bis[ $\mu 3-1$-hydroxy-2-(imidazol-3-ium1-yl)ethylidene-1,1-diphosphonato-k4O:O,O':O"]trisodium] dihydrate]. Acta Cryst: 66: m122-m126.

20. Freire E, Vega DR, Baggio R (2010) Zoledronate complexes. III. Two zoledronate complexes with alkaline earth metals: $[\mathrm{Mg}(\mathrm{C} 5 \mathrm{H} 9 \mathrm{~N} 2 \mathrm{O} 7 \mathrm{P} 2) 2(\mathrm{H} 2 \mathrm{O}) 2]$ and [Ca(C5H8N2O7P2)(H2O)]n. Acta Cryst: C66: m166-m170.

21. Freire E, Vega D (2009) Diaquabis[1-hydroxy-2-(imidazol-3-ium-1-yl)-1,1'ethylidenediphophonato-K2O,O']zinc(II). Acta Cryst: E65: m1428-m1429.

22. Chen LX, Zhou Z-R, Li Y-L, Ning Z-G, Zhang T-S, et al. (2015) Comparison of Bone Mineral Density in Lumbar Spine and Fracture Rate among Eight Drugs in Treatments of Osteoporosis in Men: A Network Meta-Analysis. PLOS One 10: e0128032.

23. Brouwers JEM, Ruchelsman M, Rietbergen Bv, Bouxsein ML (2009) Determination of rat vertebral bone compressive fatigue properties in untreated intact rats and zoledronic-acid-treated, ovariectomized rats. Osteoporos Int 20: 1377-1384.

24. Shuai B, Shen L, Yang Y, Ma C, Zhu R, et al. (2015) Assessment of the Impact of Zoledronic Acid on Ovariectomized Osteoporosis Model Using Micro-CT Scanning. PLoS One 10: e0132104.

25. Carbonare LD, Zanatta M, Gasparetto A, Valenti MT (2010) Safety and tolerability of zoledronic acid and other bisphosphonates in osteoporosis management. Drug Healthc Patient Saf 2: 121-137.

26. Pereira FRA, Dutra RC, Olímpio TCR, Muller SS, Palacio EP (2009) Effects of zoledronic acid on ooforectomized rats' tibiae: a prospective and randomized study. Rev Bras Ortop 44: 61-68.

27. Lewiecki EM (2009) Intravenous zoledronic acid for the treatment of osteoporosis: The evidence of its therapeutic effect. Core Evidence 4: 13-23. 